\title{
TOPICAL USE OF TRANEXAMIC ACID IN CORONARY ARTERY BYPASS OPERATIONS: A DOUBLE-BLIND, PROSPECTIVE, RANDOMIZED, PLACEBO-CONTROLLED STUDY
}

\author{
Michele De Bonis, $\mathrm{MD}^{\mathrm{a}}$ \\ Franco Cavaliere, $\mathrm{MD}^{\mathrm{b}}$ \\ Francesco Alessandrini, MD \\ Elisabetta Lapenna, MD \\ Filippo Santarelli, $\mathrm{MD}^{\mathrm{a}}$ \\ Umberto Moscato, $\mathrm{MD}^{\mathrm{c}}$ \\ Rocco Schiavello, $\mathrm{MD}^{\mathrm{b}}$ \\ Gian Federico Possati, MD
}

Objectives: We sought to investigate the effect of topical application of tranexamic acid into the pericardial cavity in reducing postoperative blood loss in coronary artery surgery. Methods: A prospective, randomized, double-blind investigation with parallel groups was performed. Forty consecutive patients undergoing primary coronary surgery were randomly assigned to group 1 (tranexamic acid group) or group 2 (placebo group). Tranexamic acid $(1 \mathrm{~g}$ in $100 \mathrm{~mL}$ of saline solution) or placebo was poured into the pericardial cavity and over the mediastinal tissues before sternal closure. The drainage of mediastinal blood was measured hourly. Results: Chest tube drainage in the first 24 hours was $485 \pm 166 \mathrm{~mL}$ in the tranexamic acid group and $641 \pm 184 \mathrm{~mL}$ in the placebo group $(P=.01)$. Total postoperative blood loss was $573 \pm 164 \mathrm{~mL}$ and $739 \pm 228 \mathrm{~mL}$, respectively $(P=.01)$. The use of banked donor blood products was not significantly different between the two groups. Tranexamic acid could not be detected in any of the blood samples blindly collected from 24 patients to verify whether any systemic absorption of the drug occurred. There were no deaths in either group. None of the patients required reoperation for bleeding. Conclusions: Topical application of tranexamic acid into the pericardial cavity after cardiopulmonary bypass in patients undergoing primary coronary bypass operations significantly reduces postoperative bleeding. Further studies must be carried out to clarify whether a more pronounced effect on both bleeding and blood products requirement might be seen in procedures with a higher risk of bleeding. (J Thorac Cardiovasc Surg 2000;119:575-80)

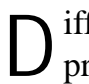
iffuse microvascular bleeding remains a common problem after myocardial revascularization with cardiopulmonary bypass (CPB). The hemorrhagic diathesis associated with CPB is widely known. It results from a multifactorial coagulopathy in which the predominant factors are thrombocytopenia, acquired platelet dysfunction, ${ }^{1}$ loss of clotting factors, ${ }^{2}$ unneutralized heparin, and increased fibrinolysis. ${ }^{3}$ Bleeding necessitating re-exploration occurs in $2 \%$ to $7 \%$ of

From the Departments of Cardiac Surgery, ${ }^{\mathrm{a}}$ Anesthesiology, ${ }^{\mathrm{b}}$ and Institute of Hygiene and Public Health, ${ }^{c}$ Catholic University, Rome, Italy.

Received for publication July 15, 1999; revisions requested Sept 20, 1999; revisions received Oct 25, 1999; accepted for publication Oct 26, 1999.

Address for reprints: Michele De Bonis, MD, Via Graziano 18, 00165 Roma, Italy.

Copyright $@ 2000$ by Mosby, Inc.

0022-5223/2000 $\$ 12.00+0 \quad \mathbf{1 2 / 1 / 1 0 4 0 3 5}$

doi: $10.1067 / \mathrm{mtc} .2000 .104035$ patients after $\mathrm{CPB}$, and $50 \%$ to $80 \%$ of them will not have an identifiable surgical bleeding source. ${ }^{4}$ Fibrinolysis has been reported to be the cause of $25 \%$ to $45 \%$ of significant postbypass bleeding. ${ }^{5}$ Various antifibrinolytic agents have been used to diminish postbypass bleeding. These include $\varepsilon$-aminocaproic acid, ${ }^{6}$ aprotinin, ${ }^{7,8}$ and, most recently, tranexamic acid (TA). ${ }^{9,10}$ TA is a synthetic antifibrinolytic drug that acts by attaching to the lysine-binding sites of plasmin and plasminogen. ${ }^{11}$ Saturation of these sites displaces plasminogen from its fibrin surface, thereby inhibiting fibrinolysis. TA is 7 to 10 times more potent than $\varepsilon$ aminocaproic acid and is far less expensive than aprotinin. ${ }^{12}$ Intravenous TA administration has been associated with an increased risk of thromboembolic complications and early graft closure in coronary artery bypass grafting (CABG)., ${ }^{73}$ It has been demonstrated that local antifibrinolytic activity provided by topical application of TA is effective in preventing bleeding after oral surgery in patients with hemophilia ${ }^{14}$ and in 
patients who are being treated with anticoagulants. ${ }^{15}$ Topical TA has also been successfully used in epistaxis, ${ }^{12}$ bladder surgery, ${ }^{12}$ and gynecologic hemorrhages. ${ }^{16}$ This prospective, double-blind, randomized, placebo-controlled study was designed to investigate the effect of topical TA in reducing postoperative blood loss in coronary artery surgery.

\section{Methods}

After institutional approval was obtained, all patients scheduled for first-time elective CABG between March 1998 and November 1998 were eligible for enrollment. Contraindications for enrollment included associated valve surgery or any other combined procedure, administration of platelet-activating drugs within 14 days of operation, bleeding diathesis, history of thrombosis, creatinine levels of greater than $160 \mathrm{mg} / \mathrm{dL}$, heparin administration within 48 hours of operation, nonsteroidal anti-inflammatory medication within 3 days, or a known allergy to TA. During this 9month period, 214 patients underwent elective primary coronary surgery at our institution. Forty patients met the requirements for inclusion, and informed consent was obtained from all of them. The study was carried out as a prospective, randomized, double-blind investigation with parallel groups. The aim was to compare the hemostatic effect of a $100-\mathrm{mL}$ saline solution containing $1 \mathrm{~g}$ of TA with that of a $100-\mathrm{mL}$ placebo saline solution. These two 100-mL solutions were prepared in advance by the hospital pharmacy in identical bottles marked "A" and "B" and delivered to the operating theaters. TA (Tranex; Malesci Istituto Farmacobiologico, Firenze, Italy), in ampules of $5 \mathrm{~mL}$ containing $100 \mathrm{mg}$ of TA per milliliter of saline solution without any other additives or preservatives, was used for this purpose.

Randomization was carried out with random-number tables by a research nurse attached to the Department of Cardiac Surgery but not to the operating theaters. Sealed envelopes were prepared and left in a box in the operating theater. On the day of surgery, the theater nurse selected the next card from the box, and this determined which solution was to be used. Neither the surgeons, anesthetists, scrub nurses, nor the perfusionists knew the composition of the solution administered. Forty consecutive patients were randomly assigned to group 1 (TA group) or group 2 (placebo group). Only two cardiac surgeons were responsible for the surgical hemostasis. The anesthetic management and conduct of CPB were standardized. All patients were premedicated with diazepam 0.1 to 0.15 $\mathrm{mg} / \mathrm{kg}$ administered orally, morphine 0.1 to $0.15 \mathrm{mg} / \mathrm{kg}$ administered intramuscularly, and scopolamine $0.01 \mathrm{mg} / \mathrm{kg}$ administered intramuscularly. Anesthesia was induced with fentanyl 3 to $5 \mu \mathrm{g} / \mathrm{kg}$ and thiopental $3 \mathrm{mg} / \mathrm{kg}$ and maintained with boli of fentanyl 100 to $200 \mu \mathrm{g}$ and midazolam $2.5 \mathrm{mg}$. Arterial hypertension was controlled by isoflurane administration. Muscle paralysis was obtained with pancuronium bromide $0.1 \mathrm{mg} / \mathrm{kg}$. After endotracheal intubation, patients were connected to a Servo Ventilator D (Siemens, Solna, Sweden). Minute volume and fraction of inspired oxygen were adjusted to achieve arterial $\mathrm{PCO}_{2}$ values between 30 and $45 \mathrm{~mm} \mathrm{Hg}$ and arterial $\mathrm{Po}_{2}$ values between 100 and $150 \mathrm{~mm} \mathrm{Hg}$. The extracorporeal circuit consisted of a hollow-fibber membrane oxygenator (Terumo Capiox E; Terumo Co, Tokyo, Japan). Polyvinyl chloride tubing was used throughout the circuit, except for the roller pump tubing, which was silicone rubber. Before CPB was established, each patient received $3 \mathrm{mg} / \mathrm{kg}$ bovine lung heparin; when the activated clotting time was shorter than 400 seconds, additional doses of heparin were administered. Heparin was reversed with protamine sulfate at a 1.3:1 ratio. Normothermia at $37^{\circ} \mathrm{C}$ and isothermic intermittent antegrade administration of blood potassium cardioplegic solution were used in all patients. Left internal thoracic artery grafts supplemented with saphenous vein grafts were routinely used. The left pleural space was opened intentionally during left internal thoracic artery harvesting. Before closure of the median sternotomy, mediastinal and thoracic drains were clamped, and $100 \mathrm{~mL}$ of saline solution (with or without 1000 $\mathrm{mg}$ of TA) at room temperature was poured into the pericardial cavity and over the mediastinal tissues. The clamps on the mediastinal and thoracic drains were released after closure of the median sternotomy.

After the patient was transferred to the intensive care unit, continuous low-grade suction $\left(5 \mathrm{~cm} \mathrm{H}_{2} \mathrm{O}\right)$ was applied, which was supplemented with periodic milking of the drains. Complete blood count, SMA-18 (Technicon Instruments Corp, Tarrytown, NY), prothrombin time, partial thromboplastin time, and platelet counts were measured before the operation and when the patients arrived at the intensive care unit. The drainage of mediastinal blood was measured hourly. The mediastinal and thoracic drains were removed when the total drainage was less than $240 \mathrm{~mL}$ over the previous 24 hours. Uniform transfusion criteria were adhered to in all patients. Blood and blood components were administered only when the hematocrit level fell to less than 0.24 or the hemoglobin level fell to $7.5 \mathrm{~g} / \mathrm{L}$ in the postoperative period. Shed mediastinal blood was not transfused into any patient during this study. The number of grafts, duration of CPB, crossclamp time, incidence of reoperation for bleeding, and amount of total chest tube drainage were recorded for all patients. The plasma concentration of TA levels was assayed by electron-capture gas chromatography 2 hours after unclamping of the chest tubes to verify whether any systemic absorption of this antifibrinolytic agent occurred after its topical application into the pericardial cavity. ${ }^{15,17}$

Means and SDs were reported provided that no significant deviations from normal distribution were observed graphically and with the Kolmogorov-Smirnov test. Differences between the two groups of patients concerning hematologic and coagulative parameters were analyzed by the 2-tailed, unpaired, Student $t$ test. Data about blood loss during the first 24 postoperative hours were analyzed by 2 -way analysis of variance (ANOVA) (TA vs placebo groups; time subdivided into 3-hour intervals) for repeated measures. The comparison of the blood loss during each 3-hour interval between the TA and placebo groups was carried out by linear contrast, as well as the comparison of the total amount of chest drainage after 
Table I. Patient demographics

\begin{tabular}{lccc}
\hline & \multicolumn{3}{c}{ Placebo } \\
& TA group & group & P value \\
\hline Age (y) & $62 \pm 7$ & $60 \pm 6$ & .2 \\
M/F & $17 / 3$ & $18 / 2$ & \\
Crossclamp time (min) & $55 \pm 17$ & $62 \pm 14$ & .1 \\
Bypass time (min) & $64 \pm 18$ & $75 \pm 14$ & .07 \\
Internal thoracic artery graft & $100 \%$ & $100 \%$ & \\
Average grafts per patient & $2.7 \pm 0.7$ & $3 \pm 0.6$ & .2 \\
Intensive care unit stay (h) & $47 \pm 35$ & $43 \pm 25$ & .6 \\
\hline
\end{tabular}

Values are means $\pm \mathrm{SD}$ where shown.

the first 24 postoperative hours. The difference in total postoperative bleeding was analyzed by using the 2-tailed, unpaired, Student $t$ test because the chest tubes were removed after a variable interval of time. Statistical analyses were made by using Statistica for Windows software (Statsoft Inc, Tulsa, Okla).

\section{Results}

The two groups were matched with regard to age, sex, duration of operation, CPB time, and average number of distal anastomoses (Table I). There was no bias in the distribution of anesthesiologists and surgeons between the two groups. Preoperative and postoperative hemoglobin concentrations, hematocrit levels, platelet counts, prothrombin times, and partial thromboplastin times were not significantly different between the two groups (Tables II and III). No statistically significant differences were found in the dosage of heparin or protamine administered during the operations. Chest tube drainage in the first 24 hours was 485 $\pm 166 \mathrm{~mL}$ in the TA group and $641 \pm 184 \mathrm{~mL}$ in the placebo group $(P=.01)$. This represents about a $25 \%$ decrease in blood loss. Total postoperative chest tube drainage was $573 \pm 164 \mathrm{~mL}$ (range, $360-1020 \mathrm{~mL}$ ) in the TA group and $739 \pm 228 \mathrm{~mL}$ (range, $365-1310 \mathrm{~mL}$ ) in the placebo group $(P=.01)$, which corresponds to a $22 \%$ decrease in total bleeding. In addition, chest tube drainage was compared between the two groups every 3 hours after operation (Fig 1). Blood loss from 0 to 3 hours was reduced by $36 \%$ in the TA group compared with that in the placebo group (172 \pm 81 vs $268 \pm 95$ $\mathrm{mL}, P<.001)$. In the following 3 -hour intervals, the amount of blood loss in the TA group was lower than that found in the placebo group, but these differences were not statistically significant. Intraoperative and postoperative use of banked donor blood products was not significantly different between the two groups. Three (15\%) patients in the TA group and 4 (20\%) patients in the placebo group required an average of 2.3
Table II. Preoperative hematologic profile

\begin{tabular}{lccc}
\hline & \multicolumn{3}{c}{ Placebo } \\
& TA group & group & P value \\
\hline Platelets $\left(10^{3}\right)$ & $163 \pm 30$ & $160 \pm 52$ & .8 \\
Prothrombin time (s) & $12.4 \pm 0.9$ & $14.5 \pm 1.6$ & .2 \\
Partial thromboplastin time (s) & $29.6 \pm 5.2$ & $34.3 \pm 14.3$ & .2 \\
Hemoglobin $(\mathrm{g} / \mathrm{dL})$ & $12.1 \pm 0.8$ & $11.6 \pm 1.4$ & .2 \\
Hematocrit $(\%)$ & $36 \pm 3.5$ & $35.4 \pm 4.9$ & .2 \\
Fibrinogen $(\mathrm{mg} / \mathrm{dL})$ & $210 \pm 84.6$ & $249 \pm 54.9$ & .09 \\
\hline
\end{tabular}

Values shown are means \pm SD.

Table III. Postoperative hematologic profile

\begin{tabular}{lccc}
\hline & \multicolumn{3}{c}{ Placebo } \\
& TA group & group & P value \\
\hline Platelets $\left(10^{3}\right)$ & $113 \pm 34$ & $113 \pm 32$ & .9 \\
Prothrombin time (s) & $17 \pm 2.6$ & $16.8 \pm 1.5$ & .8 \\
Partial thromboplastin time (s) & $40.8 \pm 17$ & $43.2 \pm 35$ & .9 \\
Hemoglobin (g/dL) & $9.2 \pm 1.5$ & $8.9 \pm 1.1$ & .4 \\
Hematocrit $(\%)$ & $26.9 \pm 3.6$ & $25.6 \pm 3$ & .3 \\
Fibrinogen (mg/dL) & $218 \pm 71$ & $188 \pm 38$ & .1 \\
\hline
\end{tabular}

Values shown are means \pm SD.

and 2.2 packed red blood cell units, respectively (1 unit $=$ approximately $360 \mathrm{~mL}$ ). No fresh frozen plasma, cryoprecipitate, or platelets were transfused in any group. Blood samples for determination of TA levels were blindly collected 2 hours after unclamping of the chest tubes from 24 patients: 13 belonged to the TA group and 11 to the placebo group. None of these patients had detectable levels of TA. There were no deaths in either group. None of the patients required reoperation for bleeding. One patient in the placebo group had a perioperative myocardial infarction, as indicated by electrocardiographic and echocardiographic changes and plasma concentrations of cardiac enzymes.

\section{Discussion}

Various clinical studies have shown that intravenous administration of TA is effective in decreasing postoperative bleeding and transfusions in primary $\mathrm{CABG}$, as well as in reoperative cardiac surgery. ${ }^{9} 10,18$ TA is a synthetic antifibrinolytic drug that acts by attaching to the lysine-binding sites of plasmin and plasminogen. ${ }^{11}$ Saturation of these sites displaces plasminogen from the fibrin surface, inhibiting fibrinolysis. Moreover, TA inhibits plasmin-induced platelet activation, consequently preserving platelet function. ${ }^{19}$ In the effort to reduce postoperative blood loss after CPB by using antifibrinolytic agents, the benefit must always be discussed in reference to a potential increased risk of thromboembolic complications. Indeed, cases of cerebral, ${ }^{20,21}$ pul- 


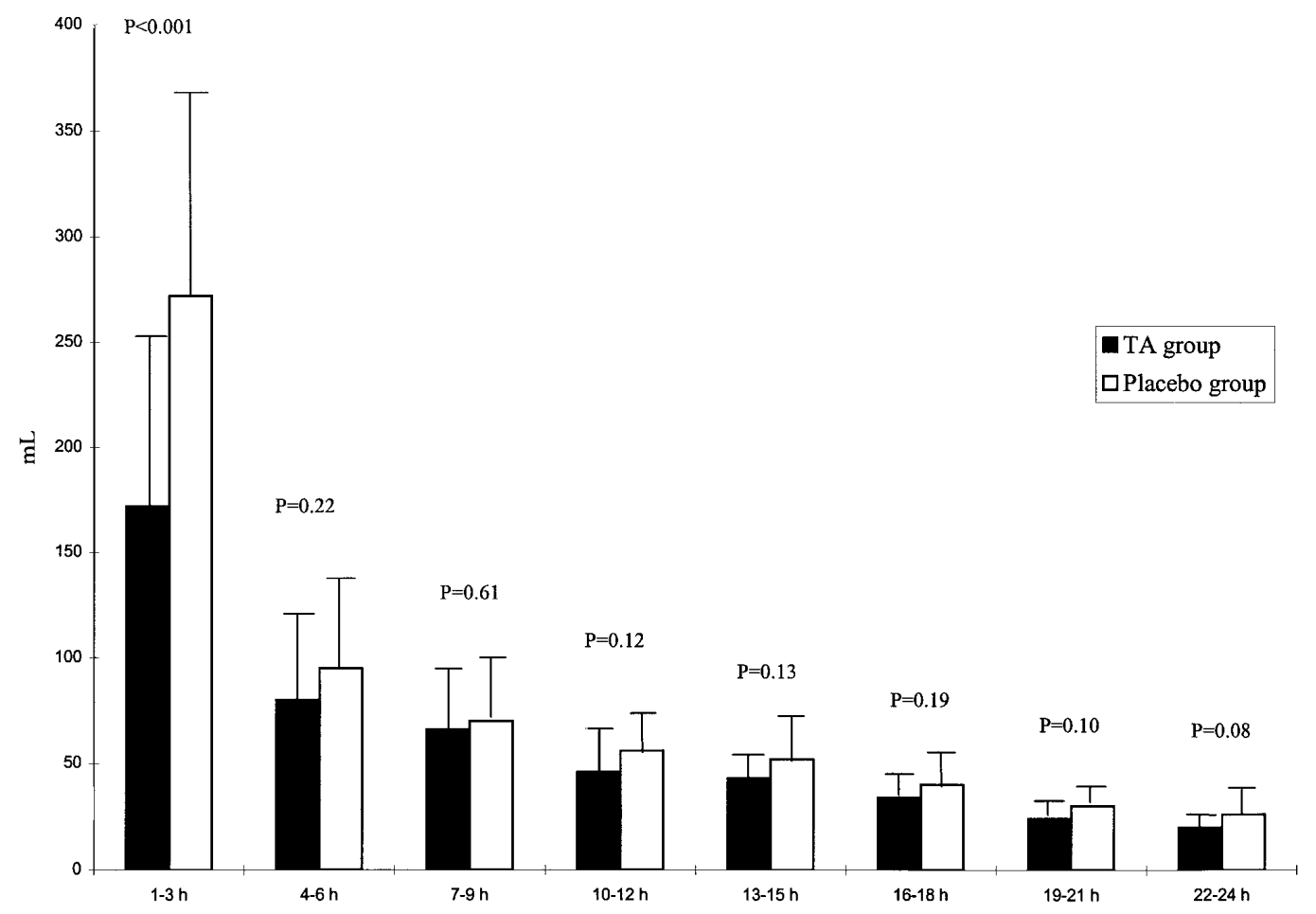

Fig 1. Postoperative blood loss measured every 3 hours.

monary, ${ }^{22}$ mesenteric, ${ }^{23}$ and retinal ${ }^{24}$ thrombosis have been described with intravenous administration of TA. Moreover, two studies have suggested that in CABG operations the use of aprotinin or TA may be associated with an increased incidence of early graft occlusion and postoperative myocardial infarction, although both studies failed to achieve statistical significance. ${ }^{7,13}$ Recently, the International Multicenter Aprotinin Graft Patency Experience Trial documented that high-dose aprotinin administered prophylactically to patients with primary CABG increases the probability of early saphenous vein graft occlusion. ${ }^{25}$

In the effort to reduce postoperative bleeding, antifibrinolytic agents have also been applied topically into the pericardial cavity. ${ }^{26,27}$ Tatar and colleagues ${ }^{26}$ first reported in 1993 that the topical use of aprotinin reduces postoperative blood loss and the need for transfusion in coronary artery surgery. The fact that aprotinin could not be detected in the patients' blood suggested that its effect was likely due to topical action. Similar results were described by the Oxford group. ${ }^{27}$ Thus far, to the best of our knowledge, no prospective, randomized, double-blind study has been published concerning the topical use of TA in the pericardial cavity after myocardial revascularization. However, the hemostatic effect of topical TA in oral surgery, ${ }^{14,15}$ bladder surgery, ${ }^{12}$ and gynecologic hemorrhage ${ }^{16}$ has been demonstrated. The present study showed that a single 1-g dose of TA applied into the pericardial cavity after primary $\mathrm{CABG}$ reduces blood loss by $36 \%$ during the first 3 hours and by $25 \%$ during the first 24 hours after operation in comparison with placebo. The reduction in blood loss occurs principally in the initial 3 postoperative hours. We believe that this may be due to the early hemostatic effect provided by topical TA. It has been suggested that a local fibrinolytic state persists after closure of the thoracic cavity and contributes to the postoperative blood loss. ${ }^{28}$ The application of TA into the chest before closure of the median sternotomy could remove plasminogen from the fibrin surface of clots, thereby inhibiting plasmin-induced degradation of fibrin. Thus it might prevent the resolution of formed clots and lead to hemostasis by preserving their integrity. On the other hand, TA could not be detected in any of the blood samples collected from the 13 patients of the treatment group 2 hours after unclamping of the chest tubes. No studies are currently available regarding the absorption and fate of TA after topical application into the pericardial cavity. However, the pharmacokinetics of this drug after intravenous, oral, and intramuscular administration ${ }^{17}$ allowed us to extrapolate that after 2 hours we would expect to detect TA in 
the plasma if any significant absorption had occurred. The therapeutic plasma level of TA is approximately 10 to $15 \mathrm{mg} / \mathrm{mL}$. The electron-capture gas chromatography has been successfully used for the determination of levels of TA in plasma as low as $0.2 \mathrm{mg} / \mathrm{mL} .{ }^{17}$ In our opinion the fact that TA could not be detected in any of the blood samples collected strongly suggests that the drug remained restricted to the pericardial space and that its effect was due to topical action. We appreciate, however, that a proper pharmacokinetic study needs to be done to definitely clarify this issue. Our data demonstrate that the reduction in blood loss in the treatment group was statistically significant in the initial 3 hours after operation but not in the following 21 hours. It is likely that the $1 \%$ solution of TA used in this series was not sufficient to suppress local fibrinolysis for more than 3 to 4 hours. We believe that a larger dose of TA (eg, a 5\% solution) could prolong the hemostatic effect of this drug. This hypothesis is in accordance with previously reported results of treatment in anticoagulanttreated patients undergoing oral surgery. ${ }^{15}$

We are aware that in the current study the total reduction in blood loss in the TA group compared with that found in the placebo group was less than $200 \mathrm{~mL}$ and therefore relatively small, although statistically significant. However, if we define excessive bleeding as total chest drainage of more than 700 to $800 \mathrm{~mL}$, it should be stressed that most patients in this series bled little. Minimal bleeding overall might have helped hide the hemostatic efficacy of this pharmaceutical agent. Little postoperative bleeding was the result of both meticulous surgical hemostasis and the relatively low risk for bleeding of our population. All the patients were undergoing primary $\mathrm{CABG}$ with normothermic $\mathrm{CPB}$, did not receive platelet-activating drugs within 14 days of operation, and did not have any kind of bleeding diathesis. Furthermore, only the left internal thoracic artery was routinely used as in situ arterial graft. A greater effect of topical TA in reducing blood loss could possibly occur in more prolonged and complex procedures with a higher risk of bleeding.

The failure of the current study to document a reduction in allogenic transfusions despite a statistically significant reduction in blood loss may be related to several factors: little overall postoperative bleeding, stringent transfusion criteria, and sample size insufficient to demonstrate a modest effect. When surgical blood loss is already minimal, the beneficial effect of the drug on consumption of blood products is likely to be small, ${ }^{29}$ particularly if transfusion practice follows stringent guidelines. Indeed, the criteria we adopted required a hematocrit level of less than $24 \%$ to trigger a transfusion, thus providing an overall low incidence of transfusions. Because mean postoperative hematocrit levels exceeded $25 \%$ for each group, a group difference in transfusions would be unexpected. The practice of transfusion to a higher hematocrit level, such as a level of less than $30 \%$ rather than $24 \%$, could more easily demonstrate an effect of topical TA on transfusion requirement.

The economic effect on the hospital's budget of the topical method described seems to be little. At our institution, $1000 \mathrm{mg}$ of TA costs $\$ 2.50$, whereas $1,000,000 \mathrm{kIU}$ of aprotinin, as topically used by Tatar and colleagues, ${ }^{27}$ has a price of $\$ 62$. $\varepsilon$-Aminocaproic acid has a cost of $\$ 0.70$ per $1000 \mathrm{mg}$, but although there are no data about its topical use, its dosage is approximately 10 times higher than that of TA when administered intravenously. The low cost of TA is attractive, but to be fully justified, a reduction in blood loss has to be followed by a reduction in the need for transfusion requirements.

In conclusion, topical application of TA into the pericardial cavity after $\mathrm{CPB}$ in patients undergoing $\mathrm{CABG}$ operations significantly reduces postoperative bleeding in the first 3 hours after operation. This reduction in blood loss might be the consequence of the potential local antifibrinolytic effect of TA. When topical TA is used in a homogeneous population of patients with a low bleeding risk undergoing primary $\mathrm{CABG}$, the decrease in blood loss is relatively small. Moreover, no effect is observed on the prevalence of transfusions, particularly if heightened attention is given to surgical hemostasis and stringent transfusion criteria are followed. We believe that a more pronounced effect on both postoperative bleeding and blood product requirement might be seen in procedures with a higher bleeding risk (eg, redo operations, complete arterial myocardial revascularization, hypothermic $\mathrm{CPB}$, long $\mathrm{CPB}$ time, preoperative aspirin therapy, or coagulopathy). Further studies must be carried out to clarify this issue. Finally, it needs to be established whether a larger dose of topical TA could prolong the hemostatic action of this drug.

\section{REFERENCES}

1. Harker LA, Malpass TW, Branson HE, Hessel EA II, Slichter SJ. Mechanism of abnormal bleeding in patients undergoing cardiopulmonary bypass: acquired transient platelet dysfunction associated with selective alpha-granule release. Blood 1980;56: 824-34.

2. Despotis GJ, Santoro SA, Spitznagel E, Kater KM, Cox JL, Barnes P, et al. Prospective evaluation and clinical utility of onsite monitoring of coagulation in patients undergoing cardiac operation. J Thorac Cardiovasc Surg 1994;107:271-9. 
3. Kucuk O, Kwaan HC, Frederickson J, Wade L, Green D. Increased fibrinolytic activity in patients undergoing cardiopulmonary bypass operation. Am J Hematol 1986;23:223-9.

4. Verska JJ, Lonser ER, Brewer LA. Predisposing factors and management of hemorrhage following open heart surgery. J Cardiovasc Surg 1972;13:361-8.

5. Kevy SV, Glickman RM, Bernhard WF, Diamond LK, Grass RE. The pathogenesis and control of the hemorrhagic defect in open heart surgery. Surg Gynecol Obstet 1966;123:313-8.

6. Daily PO, Lamphere JA, Dembitsky WP, Adamson RM, Dans NF. Effect of prophylactic epsilon-aminocaproic acid on blood loss and transfusion requirements in patients undergoing firsttime coronary artery bypass grafting: a randomized, prospective, double-blind study. J Thorac Cardiovasc Surg 1994;108:99-105.

7. Cosgrove DM III, Heric B, Lytle BW, Taylor PC, Novoa R, Golding LA, et al. Aprotinin therapy for reoperative myocardial revascularization: a placebo-controlled study. Ann Thorac Surg 1992;54:1031-8.

8. Lemmer JH Jr, Stanford W, Bonney SL, Breen JF, Chomka EV, Eldredge WJ, et al. Aprotinin for coronary bypass operations: efficacy, safety, and influence on early saphenous graft patencya multicenter, randomized, double blind, placebo-controlled study. J Thorac Cardiovasc Surg 1994;107:543-53.

9. Horrow JC, Van Riper DF, Strong MD, Brodsky I, Parmet JL. Hemostatic effects of tranexamic acid and desmopressin during cardiac surgery. Circulation 1991;84:2063-70.

10. Nakashima A, Matsuzaki K, Fukumura F, Hisahara M, Kanegae Y, Fukae K, et al. Tranexamic acid reduces blood loss after cardiopulmonary bypass. ASAIO Trans 1993;39:185-9.

11. Longstaff C. Studies on the mechanisms of action of aprotinin and tranexamic acid as plasmin inhibitors and antifibrinolytic agents. Blood Coagul Fibrinolysis 1994;5:537-42.

12. Verstraete M. Clinical application of inhibitors of fibrinolysis. Drugs 1985;29:236-61.

13. Ovrum E, Holen EA, Abdelnoor M, Oystese R, Ringdal ML. Tranexamic acid (Cyklokapron) is not necessary to reduce blood loss after coronary artery bypass operations. J Thorac Cardiovasc Surg 1993;105:78-83.

14. Sindet-Pedersen S, Stenbjerg S. Effect of local antifibrinolytic treatment with tranexamic acid in hemophiliacs undergoing oral surgery. J Oral Maxillofac Surg 1986;44:703-7.

15. Sindet-Pedersen S, Ramtrom G, Bernvil S, Blomback M. Hemostatic effect of tranexamic acid mouthwash in anticoagulant-treated patients undergoing oral surgery. N Engl J Med 1989; 320:840-3.
16. Valsecchi A. Further notes on the topical use of tranexamic acid in the treatment of gynecological hemorrhage. Minerva Ginecol 1980;32:825-30.

17. Vessman J, Stromberg S. Determination of tranexamic acid in biological material by electron capture gas chromatography after direct derivatization in an aqueous medium. Anal Chem 1977; 49:369-73.

18. Shore-Lesserson L, Reich DL, Vela-Cantos F, Ammar T, Ergin A. Tranexamic acid reduces transfusions and mediastinal drainage in repeat cardiac surgery. Anesth Analg 1996;83:18-26.

19. Soslau G, Horrow J, Brodsky I. The effect of tranexamic acid on platelet ADP during extracorporeal circulation. Am J Hematol 1991;38:113-9.

20. Agnelli G, Gresele P, De Cunto M, Gallai V, Nenci GG. Tranexamic acid, intrauterine contraceptive devices and fatal cerebral arterial thrombosis: case report. Br J Obstet Gynaecol 1982;89:681-2.

21. Davies D, Howell DA. Tranexamic acid and arterial thrombosis [letter]. Lancet 1977;1:49.

22. Woo KS, Tse LK, Woo JL, Vallance-Owen J. Massive pulmonary thromboembolism after tranexamic acid antifibrinolytic therapy. Br J Clin Pract 1989;43:465-6.

23. Razis PA, Coulson IH, Gould TR, Findley IL. Acquired C1 esterase inhibitor deficiency. Anaesthesia 1986;41:838-40.

24. Parsons MR, Merritt DR, Ramsay RC. Retinal artery occlusion associated with tranexamic acid therapy. Am J Ophthalmol 1988; 105:688-9.

25. Alderman EL, Levy JH, Rich JB, Nili M, Vidne B, Schaff H, et al. Analyses of coronary graft patency after aprotinin use: results from the international multicenter aprotinin graft patency experience (IMAGE) trial. J Thorac Cardiovasc Surg 1998;116:71630.

26. Tatar H, Sertac C, Ufuk D, Ertugrul O, Hikmet S, Omer O, et al. Topical use of aprotinin in open heart operations. Ann Thorac Surg 1993;55:659-61.

27. O'Regan DJ, Giannopoulos N, Mediratta N, Kendall SWH, Forni A, Pillai R, et al. Topical aprotinin in cardiac operations. Ann Thorac Surg 1994;58:778-81.

28. Tabuchi N, de Haan J, Boonstra PW, van Oeveren W. Activation of fibrinolysis in the pericardial cavity during cardiopulmonary bypass. J Thorac Cardiovasc Surg 1993;106:828-33.

29. Hardy JF, Perrault J, Tremblay N, Robitaille D, Blain R, Carrier $M$. The stratification of cardiac surgical procedures according to use of blood products: a retrospective analysis of 1480 cases. Can J Anaesth 1991;38:511-7. 